\title{
Article
}

\section{The effect of C-terminal amidation on the efficacy and selectivity of antimicrobial and anticancer peptides}

Dennison, Sarah Rachel, Harris, Frederick, Bhatt, Tailip, Singh, Jaipaul and Phoenix, David Andrew

Available at http://clok.uclan.ac.uk/7627/

Dennison, Sarah Rachel ORCID: 0000-0003-4863-9607, Harris, Frederick, Bhatt, Tailip, Singh, Jaipaul ORCID: 0000-0002-3200-3949 and Phoenix, David Andrew (2009) The effect of C-terminal amidation on the efficacy and selectivity of antimicrobial and anticancer peptides. Molecular and Cellular Biochemistry, 332 (1-2). pp. 43-50. ISSN 0300-8177

It is advisable to refer to the publisher's version if you intend to cite from the work. http://dx.doi.org/10.1007/s11010-009-0172-8

For more information about UCLan's research in this area go to

http://www.uclan.ac.uk/researchgroups/ and search for <name of research Group>.

For information about Research generally at UCLan please go to http://www.uclan.ac.uk/research/

All outputs in CLoK are protected by Intellectual Property Rights law, including Copyright law. Copyright, IPR and Moral Rights for the works on this site are retained by the individual authors and/or other copyright owners. Terms and conditions for use of this material are defined in the policies page. 


\title{
The effect of C-terminal amidation on the efficacy and selectivity of antimicrobial and anticancer peptides
}

\author{
(Provisional title) \\ Frederick Harris ${ }^{1}$, Sarah Dennison ${ }^{2}$, Tailip Bhatt ${ }^{1}$ Jaipul Singh $^{1}$ and David A \\ Phoenix ${ }^{3}$ \\ ${ }^{1}$ School of Forensic and Investigative Sciences, \\ ${ }^{2}$ School of Pharmacy and Pharmaceutical Sciences, \\ ${ }^{3}$ Dave's info \\ University of Central Lancashire, Preston PR1 2HE, UK. \\ Corresponding author: Prof D. A. Phoenix, Office of the Vice Chancellor, Adelphi Building, \\ University of Central Lancashire, Preston, PR1 2HE, UK., Tel: +44 (0) 1772 89***,
} Fax: +44 (0) $177289 * * *$,

E-mail: daphoenix@uclan.ac.uk. 


\begin{abstract}
Cationic defence peptides show high therapeutic potential as antimicrobial and anticancer agents. Some of these peptides carry a C-terminal amide moiety which appears to be required for antimicrobial activity. However, whether this is a general requirement and whether $\mathrm{C}$-terminal amidtion is required for the anticancer activity of defence peptides is unclear. In reponse, we analyse the toxicity of a series of Cterminally amidated defence peptides and their non-amidated isoforms to normal fibrolast cells, a variety of tumour cells and bacterial cells. The toxicities of these peptides to microbial and cancer cells were generally $<200 \mu \mathrm{M}$ and could either be unaffected by C-terminal amidation or show up to ten-fold decreases or increases. However, these peptides all showed toxcity to normal fibrolast cells with levels (generally $<150 \mu \mathrm{M}$ ) that were comparable to those of their antimicrobial and anticancer activities. In combination, these results clearly show that the C-terminal amidation of defence peptides has a variable effect on their antimicrobial and anticancer efficacy but no effect on their selectivity for these cell types.
\end{abstract}




\section{Introduction}

The increasing occurrences of resistance to antimicrobial and anticancer agents are two major problems facing medical research and defence peptides are attractive propositions for the solution of both problems. These peptides have a major advantage over conventional antibiotics and anticancer drugs in that currently microbes and tumours show little evidence of resistance to their toxic action, which involves relatively non-specific interactions with target cell membranes (REF). Nonetheless, a full understanding of factors influencing the antimicrobial and anticancer activities of defence peptides is still lacking, which hampers development of their full therapeutic potential (Hoskin et al., 2008; Amaral et al., 2007).

It is generally accepted that the ability of defence peptides to kill microbes and cancer cells primarily depends upon their positive charge, which enables electrostatic binding to anionic components of the target cell membrane, and their structural amphiphilicity, which facilitates bilayer penetration and disruption with cell death resulting. It is also well established that the positive charge carried by defence peptides mainly derives from the presence of lysine and arginine residues within their sequences (Dennison et al., 2005). However, the positive charge of some defence peptides also includes a contribution from a C-terminal amide moiety and there is evidence to suggest that the presence of this amide group enhances the antimicrobial activity of some defence peptides. Examples where this has been demonstrated include: the $\alpha$-helical amphibian peptide, PGLa (Strandberg et al., 2007), the $\beta$-sheet human $\alpha$-defensin, HNP2 (Xie et al., 2005), and the turn / turn porcine peptide, tritrpticin (Schibli et al., 2006).

Over the last decade, it has become clear that the antimicrobial and anticancer actions of defence peptides show similarities. In particular, the ability of defence peptides kill cancer cells also involves electrostatic interactions between these cationic peptides and anionic components of the cancer cell membrane (Dennison et al., 2005). Based on this observation, it has recently been suggested that C-terminal amidification may enhance the anticancer activity of defence peptides (Apponyi et al., 2004) although little research into this possibility appers to have been undertaken. Here, we have investigated these suggestions by assembling a database of Cterminally amidated peptides along with their non-amidated isoforms and analysed their toxicity to a variety of eukaryotic and prokaryotic cells. 


\section{Methods}

\section{Database assembly and cell line toxicity analysis}

The sequences of a series of C-terminally amidated (AM) peptides along with their non-C-terminally amidated (AC) isoforms (Table 1) were extracted from a database of naturally occurring and synthetic defence peptides (Owen, 2005). Toxicity data for these AC / AM isoforms against WI38, a normal fibroblast cell line of the lung diploid cells, and a variety tumour cell lines were extracted as the half lethal dose $\left(\mathrm{LD}_{50}\right)$. These tumour cell lines included MCF7 - a breast adenocarcinoma tumour cell line, SW480 - a colon adenocarcinoma tumour cell line, BMKC - a cloned melanoma cell line, H1299 - a lung large cell carcinoma tumour cell line, HeLaS3 - a cervical epithelial carcinoma cell line and PC3 - a prostate adenocarcinoma tumour cell line. Also extracted was toxicity data for these AC / AM isoforms (Table 1) against Escherichia coli (Accession number ATCC 25922), Pseudomonas aeruginosa (Accession number ATCC 27853) and Staphylococcus aureus (Accession number ATCC 25923) as the minimum inhibitory concentration (MIC). These various toxicity data were then graphically represented and compared to detect putative relationships between the toxicity levels of these peptides and their possession of C-terminal amidation.

\begin{tabular}{|c|l|}
\hline Name & \multicolumn{1}{|c|}{ Sequence } \\
\hline Hectate AC & FALALKALKKALKKLKKALKKAL-COOH \\
\hline Hectate AM & FALALKALKKALKKLKKALKKAL-NH ${ }_{2}$ \\
\hline SB-37 AC & MPKWKVFKKIEKVGRNIRNGIVKAGPAIAVLGEAKALG-COOH \\
\hline SB-37 AC & MPKWKVFKKIEKVGRNIRNGIVKAGPAIAVLGEAKALG-NH 2 \\
\hline Shiva 10 AC & FAKKLAKKLKKLAKKLAKLALAL-COOH \\
\hline Shiva 10 AM & FAKKLAKKLKKLAKKLAKLALAL-NH ${ }_{2}$ \\
\hline FLAK06 AC & FALALKALKKLKKALKKAL-COOH \\
\hline FLAK06 AM & FALALKALKKLKKALKKAL-NH \\
\hline FLAK 26 AC & FAKKLAKLAKKLAKLAL-COOH \\
\hline FLAK 26 AM & FAKKLAKLAKKLAKLAL-NH ${ }_{2}$ \\
\hline Shiva 10(1-18) AC & FAKKLAKKLKKLAKKLAK-COOH \\
\hline Shiva 10 (1-18) AM & FAKKLAKKLKKLAKKLAK-NH ${ }_{2}$ \\
\hline CA(1-7)Shiva10(1-16) AC & KWKLFKKKTKLFKKFAKKLAKKL-COOH \\
\hline CA(1-7)Shiva10(1-16) AM & KWKLFKKKTKLFKKFAKKLAKKL-NH ${ }_{2}$ \\
\hline Modelin-5 AC & KLAKKLAKLAKLAKAL-COOH \\
\hline
\end{tabular}




\begin{tabular}{|c|l|}
\hline Modelin-5 AM & KLAKKLAKLAKLAKAL-NH \\
\hline Hecate ACV AC & VALALKALKKALKKLKKALKKAL-COOH \\
\hline Hecate AMV AM & VALALKALKKALKKLKKALKKAL-NH ${ }_{2}$ \\
\hline
\end{tabular}

Table 1: Shown above are the sequences of C-terminally amidated peptides (AM) and their non-C-terminally amidated (AC) isoforms, which were extracted from the database of Owen (2005).

\section{Results and Discussion}

Factors influencing the antimicrobial and anticancer activities of defence peptides are poorly understood. To gain further insight into these factors, the present study investigates the possibility that the C-terminal amide group carried by some defence peptides may enhance their antimicrobial and anticancer action.

To date, most studies on defence peptides have focused on their antimicrobial activity. These studies showed that C-terminal amidation is the most common posttranslational modification of defence peptides, which clearly suggested biological relevance, and led a number of recent studies to show that possession of this Cterminal moiety enhanced the antimicrobial activity of these peptides (Strandberg et al., 2007; Xie et al., 2005; Schibli et al., 2006). To test the generality of this effect, the present study compared the toxicity of a series of C-terminally amidated (AM) peptides to prokaryotic cells with that of their non-C-terminally amidated (AC) isoforms (Table 1). In general, the AM and AC isoforms in Table 1 are strongly antibacterial with levels of toxicity that lie in the range 5-150 $\mu \mathrm{M}$ (Figure 1). Consistent with the results of recent studies (Strandberg et al., 2007; Xie et al., 2005; Schibli et al., 2006), analysis of these toxicity data found that the AM isoform of FLAK 06 showed activity against Escherichia coli and Aeruginosa pseudomonas, which was up to five-fold higher than that of its AC counterpart. However, in contrast, the AC isoforms of Shiva 10 and Modelin 5 were circa fifteen-fold more effective against these organisms than the corresponding AM peptides. In all cases, the AM and AC isoforms of the remaining peptides studied showed toxicity to these Gramnegative bacteria but no correlation between isoform type and toxicity levels was observed with C-terminal amidation being seen to both decease and increase efficacy. The toxicity of the peptides in Table 1 against Gram-positive bacteria was analysed and it was found that the potency of Shiva 10 and FLAK 26 AM isoforms to 
Staphylococcus aureus was up to eight-fold higher than their AC counterparts. However, the AC isoforms of SB-37 and FLAK 06 showed potency to this organism, which was two-fold higher than that of the corresponding AM peptides. The AM and AC isoforms of the remaining peptides all showed toxicity to $S$. aureus but for each peptide, no difference in potency between isoform types was observed. These data clearly show that the toxicity of defence peptides to microbial cells can be unaffected, increased or decreased by the presence of a C-terminal amide moiety, indicating that this structural modification has a variable effect on their antimicrobial efficacy. The effect of C-terminal amidation on the microbial selectivity of these peptides was also considered. Examination of Figure 2 shows that each of the AC and AM isoforms studied was strongly toxic to the normal fibroblast cell line, W138, with toxicity levels that were in the range 5-150 $\mu \mathrm{M}$ and comparable to those of their antimicrobial activity (Figure 1). These data clearly show that C-terminal amidation of the peptides studied does not affect their selectivity for microbial cells over normal eukaryotic cells. Strongly supporting this conclusion, it was recently shown that the C-terminal amidation of some aureins, which are amphibian defence peptides, had no apparent effect on the ability of these peptides to discriminate between prokaryotic and eukaryotic cells (REF).

Based on similarities between the antimicrobial and anticancer actions of defence peptides, it has recently been suggested that C-terminal amidification may enhance activity of defence peptides against cancer cells (Apponyi et al., 2004). In general, the AM and AC isoforms in Table 1 show strong activity against cancer cells with levels that are generally in the range, 5-200 $\mu \mathrm{M}$ (Figure 2) and are therefore comparable to those of their antimicrobial potency (Figure 1). Analysis of this toxicity showed that the AM and AC isoforms of FLAK06, FLAK26, Shiva10(1-18) and Modelin-5 were toxic to all cancer cell lines studied but the toxicity of the former isoform was up to ten-fold higher than that of the latter (Figure 2). In contrast, whilst the AM and AC isoforms of SB-37 and Hectate also showed toxicity to all cancer cell lines studied, in these cases, the AC isoform showed levels of toxicity that were up to ten-fold higher than that of its AM counterpart (Figure 2). Compared to the other peptides studied, the isoforms of CA(1-7)Shiva(1-18), Hectate AC/AM and Shiva10 showed toxicity to a shorter spectrum of cancer cell lines. However, in all cases, both isoforms of these peptides showed anticancer activity with no observed correlation between isoform type and the levels of this toxicity (Figure 2). These results clearly 
show that the toxicity of defence peptides to cancer cells can be unaffected, increased or decreased by the presence of a C-terminal amide moiety, indicating that this structural modification has a variable effect on their anticancer efficacy. Moreover, as described above, each of the isoforms studied was strongly toxic to the normal fibroblast cell line, W138, indicating that C-terminal amidation does not affect the selectivity of these peptides for cancer cells over normal eukaryotic cells in general.

In summary, in contrast to previously published results on single peptides, this analysis shows that C-terminal amidification has a generic effect on either the selectivity or the efficacy of defence peptides, which needs to be considered in the context of the peptide structure and its target cell. The presence of this structural moiety had a variable effect on the toxicity of defence peptides to both microbial and cancer cells and it is generally accepted that this toxicity involves membrane invasion (Hoskin and Ramamoorthy, 2008). Thus it may be that the additional positive charge donated to these peptides by C-terminal amidation leads to changes in some physiochemical property such as amphiphilicity that influences their membrane interactivity and hence affects their efficacy against target cells.

\section{References}

Antimicrobial Sequences Database

(AMSdb; http://www.bbcm.univ.trieste.it/ tossi/search.htm)

Amaral, L., Engi, H., Viveiros, M. \& Molnar, J. (2007) Review. Comparison of multidrug resistant efflux pumps of cancer and bacterial cells with respect to the same inhibitory agents, In Vivo. 21, 237-44.

Dennison, S. R., Whittaker, M., Harris, F. \& Phoenix, D. A. (2006) Anticancer alphahelical peptides and structure/function relationships underpinning their interactions with tumour cell membranes, Curr Protein Pept Sci. 7, 487-99.

Amphiphilic alpha-helical antimicrobial peptides and their structure/function relationships Author(s): Dennison, SR; Wallace, J; Harris, F, et al. 
Source: PROTEIN AND PEPTIDE LETTERS Volume: 12 Issue: 1 Pages: 31-39 Published: JAN 2005

Times Cited: 19

Hoskin, D. W. \& Ramamoorthy, A. (2008) Studies on anticancer activities of antimicrobial peptides, Biochim Biophys Acta. 1778, 357-75.

Owen, D. R. (2005) Short bioactive peptides in, Helix BioMedix. Inc., USA, US patent: 6875744 .

Schibli’ D. J., Nguyen, L. T., Kernaghan, S. D., Rekdal, Ø. and Vogel, H. J.(2006) Structure-Function Analysis of Tritrpticin Analogs: Potential Relationships between Antimicrobial Activities, Model Membrane Interactions, and Their Micelle-Bound NMR Structures. Biophysical Journal 91, 4413-4426.

Strandberg, E., Tiltak. D., Ieronimo, M., Kanithasen, N., Wadhwani, P. and Ulrich , A. S. (2007) Influence of C-terminal amidation on the antimicrobial and hemolytic activities of cationic alpha-helical peptides. Pure and Applied Chemistry. 79, 717-728.

Xie, C., Zeng, P., Ericksen, B., Wu, Z., Luand, W. and Lu, W. (2005) Effects of the terminal charges in human neutrophil $\alpha$-defensin 2 on its bactericidal and membrane activity.
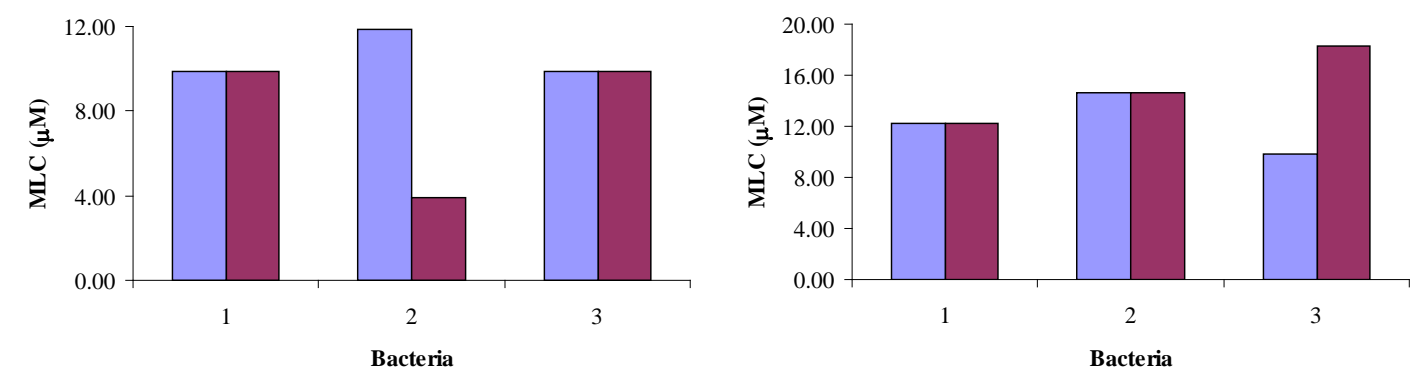

Blue bars $=$ Hecate AC, red bars $=$ Hecate AM. Blue bars $=$ SB-37 AC, red bars $=$ SB-37AM. 

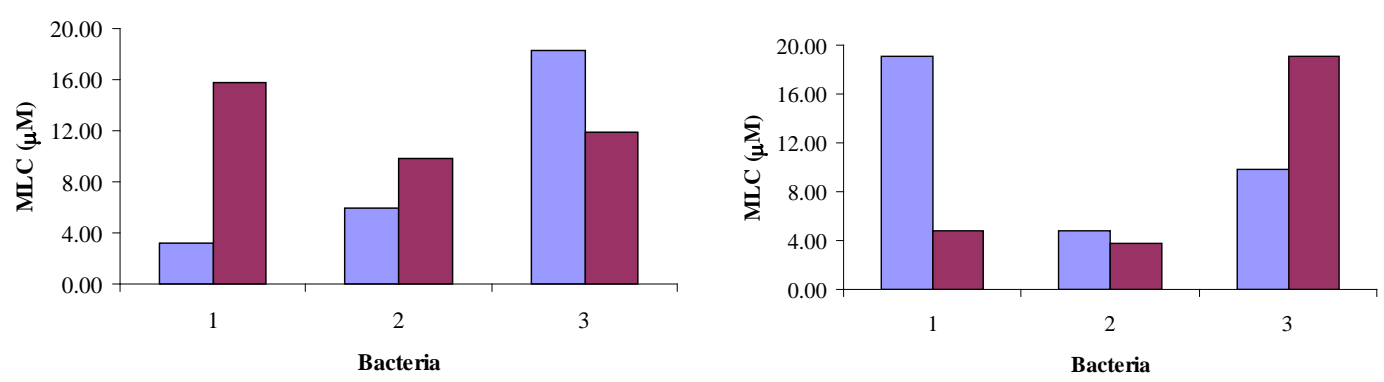

Blue bars = Shiva $10 \mathrm{AC}$, red bars $=$ Shiva 10 AM. Blue bars = FLAK 06 AC, red bars $=$ FLAK 06 AM.
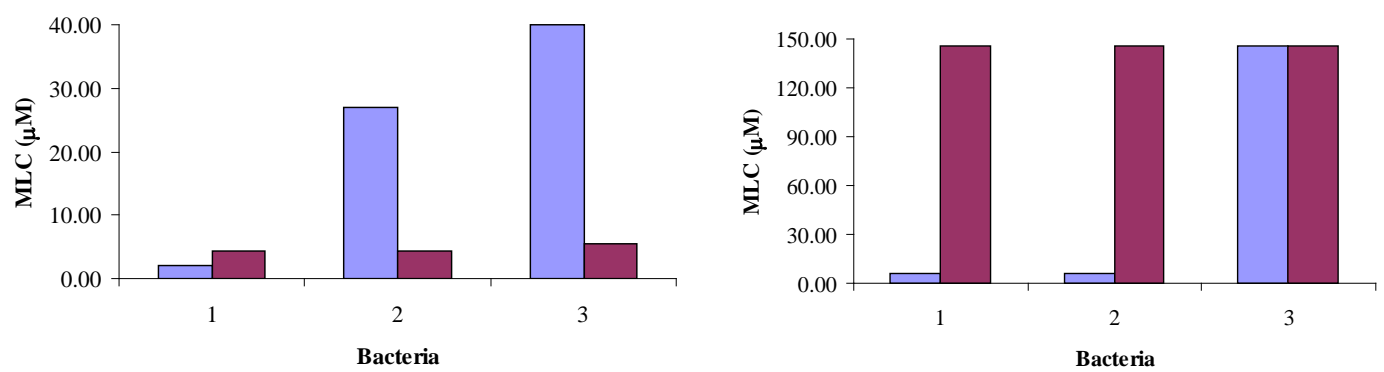

Blue bars = FLAK 26 AC, red bars = FLAK 26 AM. Blue bars = Modelin 5 AC, red bars = Modelin 5 AM.

Figure 1. The toxicity of peptides in table 1 to: $\mathbf{1}=$ Escherichia coli, accession number ATCC 25922; 2 = Pseudomonas aeruginosa, accession number ATCC 27853; 3 = Staphylococcus aureus, accession number ATCC 25923 

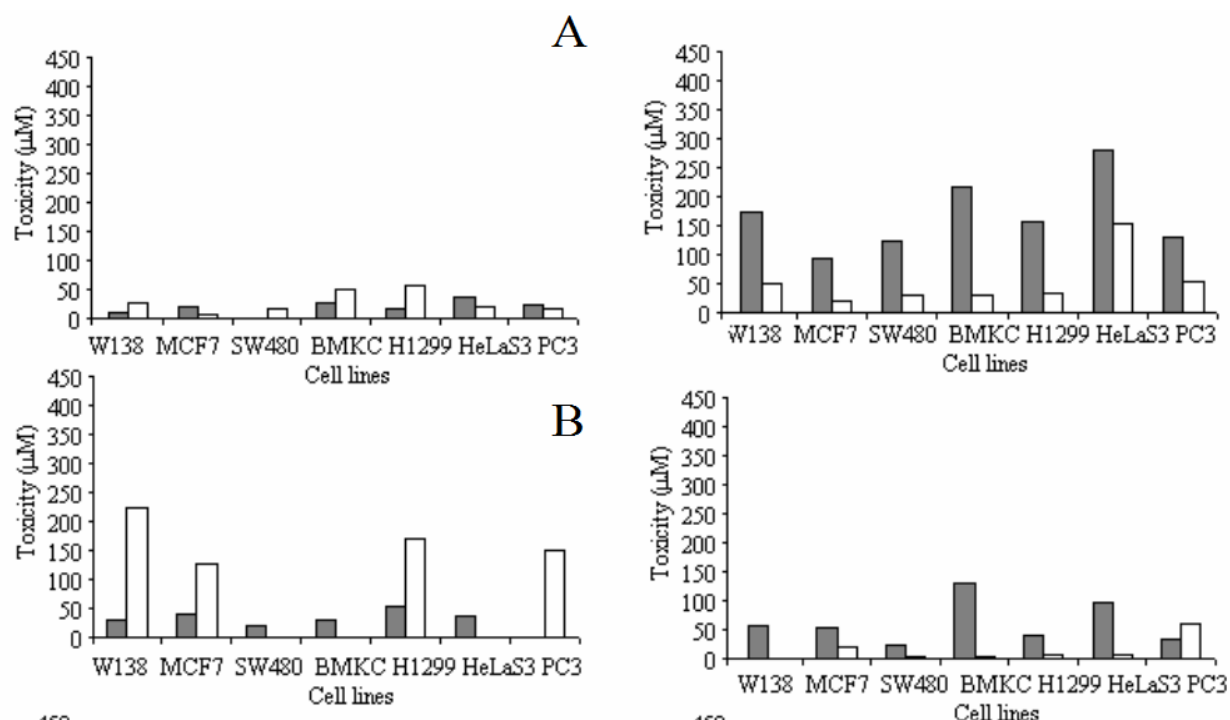

$\mathrm{F}$

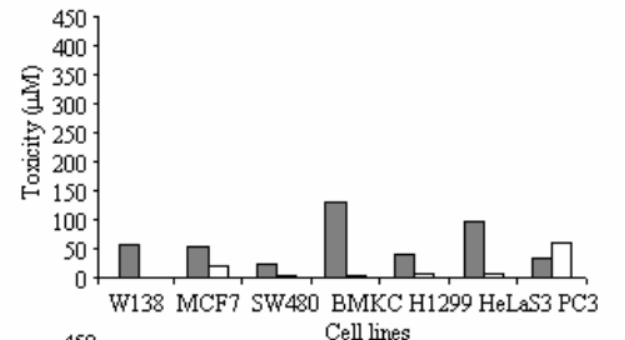

G
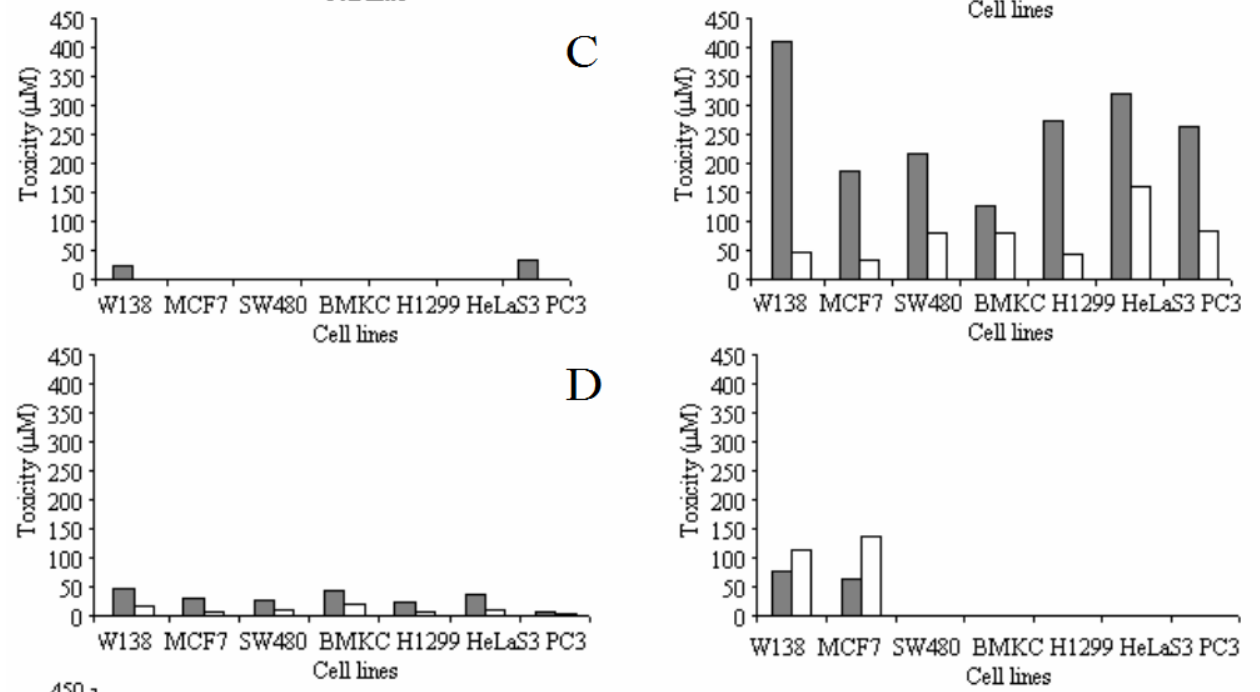

$\mathrm{H}$

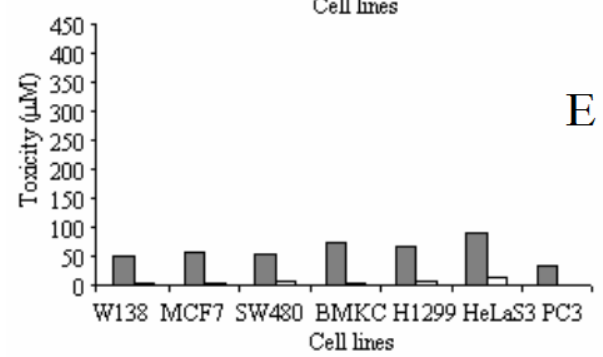

$\mathrm{E}$

Figure3. Shown above are the toxicities of individual pairs of $\mathrm{C}-\mathrm{N}$ and $\mathrm{N}-\mathrm{N}$ isoforms of ACPs (Table 1) when directed against the cell lines: WI38, MCF7, SW480, BMKC, H1299, HeLaS3 and PC3. These peptides were: Hectate AC/AM (A), SB-37 AC/AM (B), Shiva 10 AC/AM (C), FLAK 06 AC/AM (D), FLAK 26 AC/AM (E), Shiva 10(1-18) AC/AM (F), CA(1-7)Shiva10(1-16) AC/AM (G), Modelin-5 $\mathrm{COOH} / \mathrm{NH}_{2}(\mathbf{H})$ and Hectate ACV/AVM (I). For each peptide pair, the toxicity of the $\mathrm{AC}$ isoform is represented by grey bars and the AM isoform by white bars. 


\begin{abstract}
The effect of C-terminal amidation on the antimicrobial and hemolytic activities of antimicrobial peptides was studied using three cationic peptides which form amphiphilic a-helices when bound to membranes. The natural antimicrobial peptide PGLa, the designer-made antibiotic MSI-103, and the cell-penetrating "model amphipathic peptide" (MAP) are all amidated in their original forms, and their biological activities were compared with the same sequences carrying a free C-terminus. It was found that, in general, a free $\mathrm{COOH}$-terminus reduces both the antimicrobial activity and the hemolytic side effects of the peptides. The only exception was observed for MSI-103, whose antimicrobial activity was not decreased in the acid form. Having shown that the therapeutic index $(\mathrm{TI})$ of this novel peptide is significantly higher than for the other tested peptides, with high antibiotic activity and little undesired effects, we suggest that it could be a useful starting point for further development of new peptide antibiotics.
\end{abstract}

Strandberg E (Strandberg, Erik), Tiltak D (Tiltak, Deniz), Ieronimo M (Ieronimo, Marco), Kanithasen N (Kanithasen, Nathalie), Wadhwani P (Wadhwani, Parvesh), Ulrich AS (Ulrich, Anne S.)

Influence of C-terminal amidation on the antimicrobial and hemolytic activities of cationic alpha-helical peptides

Author(s): Strandberg, E; Tiltak, D; leronimo, M, et al.

Conference Information: 25th International Symposium on Chemistry of Natural Products/5th

International Conference on Biodiversity (ISCNP-25/ICOB-5), Date: JUL 23-28, 2006 Koyto JAPAN

Source: PURE AND APPLIED CHEMISTRY Volume: 79 Issue: 4 Pages: 717-728 Published: 2007 
A novel peptide, decoralin, was isolated from the venom of the solitary eumenine wasp Oreumenes decoratus. Its sequence, Ser-Leu-Leu-Ser-LeuIle-Arg-Lys-Leu-Ile-Thr, was determined by Edman degradation and corroborated by solid-phase synthesis. This sequence has the characteristic features of linear cationic $\alpha$-helical peptides; rich in hydrophobic and basic amino acids with no disulfide bond, and accordingly, it can be predicted to adopt an amphipathic $\alpha$-helix secondary structure. In fact, the CD spectra of decoralin in the presence of TFE or SDS showed a high a-helical conformation content. In a biological evaluation, decoralin exhibited a significant broad-spectrum antimicrobial activity, and moderate mast cell degranulation and leishmanicidal activities, but showed virtually no hemolytic activity. A synthetic analog with C-terminal amidation showed a much more potent activity in all the biological assays.

\title{
Decoralin, a novel linear cationic alpha-helical peptide from the venom of the solitary eumenine wasp Oreumenes decoratus Author(s): Konno, K; Rangel, M; Oliveira, JS, et al.
} Source: PEPTIDES Volume: 28 Pages: 2320-2327 Published: 2007 Times Cited: 1

Author(s): Vassilevski AA (Vassilevski, A. A.), Kozlov SA (Kozlov, S. A.), Zhmak MN (Zhmak, M. N.), Kudelina IA (Kudelina, I. A.), Dubovskii PV (Dubovskii, P. V.), Shatursky OY (Shatursky, O. Ya.), Arseniev AS (Arseniev, A. S.), Grishin EV (Grishin, E. V.)

Source: RUSSIAN JOURNAL OF BIOORGANIC CHEMISTRY Volume: 33 Issue: 4 Pages: $376-$ 382 Published: JUL 2007

\section{Times Cited: 0 References: $16 \quad$ EKCitation Map beta}

\begin{abstract}
Analogues of latarcins Ltc1 and Ltc3b, antimicrobial peptides from the venom of the Central Asian spider Lachesana tarabaevi capable of formation of amphiphilic structures in membranes without involvement of disulfide bonds, were synthesized. The amino acid sequences of the analogues correspond to immature forms of these peptides, each of them containing an additional C-terminal amino acid residue. It is concluded from the study of the biological activity of the synthesized peptides that the posttranslational C-terminal amidation of Ltc3b is a functionally important modification that ensures a high activity of the mature peptide. The lipid composition was shown to affect the interaction of synthesized peptides with artificial membranes. The analogue of Ltc3b manifested the highest activity on cholesterol-containing membranes. The mechanism of action of the studied antimicrobial peptides on membranes is discussed.
\end{abstract}


Design of perfectly symmetric Trp-rich peptides with potent and broad-spectrum antimicrobial activities

Author(s): Yang, ST; Shin, SY; Hahm, KS, et al.

Source: INTERNATIONAL JOURNAL OF ANTIMICROBIAL AGENTS Volume: 27 Issue: 4 Pages: 325-330 Published: APR 2006

Times Cited: 5

Schibli’ D. J., Nguyen, L. T., Kernaghan, S. D., Rekdal, Ø. and Vogel, H. J.(2006) Structure-Function Analysis of Tritrpticin Analogs: Potential Relationships between Antimicrobial Activities, Model Membrane Interactions, and Their Micelle-Bound NMR Structures. Biophysical Journal 91, 4413-4426.

Amidation increases the antimicrobial and......Tritrpticin, a member of the cathelicidin family, is a Trp-rich or Pro/Arg-rich peptide. Because the major requirement for an antibiotic is for it to be selective for microbes versus human cells, the efficacy of an antimicrobial peptide must be determined by comparing the antimicrobial and hemolytic activities (HA) for a given peptide (Table 2). This can best be visualized by calculating the therapeutic index for a peptide (Table 3), the ratio of its hemolytic activity to either its MIC or MBC (HA/MIC or HA/MBC). The selective nature of antimicrobial peptides has long been attributed to the differences in the membrane compositions of the outer leaflets of mammalian cells (these commonly have neutral zwitterionic phospholipids headgroups) and microbial cells (that normally have a net negative charge on their surface) $(40 \star)$. Therefore, it would be expected that increasing the net positive charge of a peptide by amidating the C-terminus should not only increase the antimicrobial activity by removing the repulsion with the phosphodiester groups, but also improve the selectivity of the peptide for microbial cells. As mentioned above, the increase in the net positive charge by amidating the C-terminus slightly increases the antimicrobial activity of tritrpticin, but there is also a corresponding increase in the hemolytic activity (Table 2). This suggests that the presence or absence of the negative charge may not improve the antimicrobial selectivity of tritrpticin. 


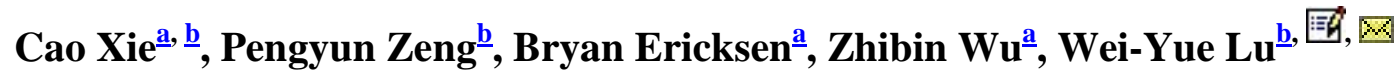
and Wuyuan LuEffects of the terminal charges in human neutrophil $\alpha$-defensin 2 on its bactericidal and membrane activity beta-sheet

a, 国, 必

anstitute of Human Virology, University of Maryland Biotechnology Institute, 725 West Lombard Street, Baltimore, MD 21201, USA ' Fudan-PharmCo Drug Target Research Center, School of Pharmacy, Fudan University, 138 Yixueyuan Road, Shanghai 200032, China

Received 4 May 2005;

revised 1 June 2005;

accepted 1 June 2005.

Available online 11 July 2005.

\section{Abstract}

Human neutrophil $\alpha$-defensin 2 (HNP2) was N-terminally acetylated and/or Cterminally amidated, resulting in three terminally modified analogs, Ac-HNP2, HNP2- $\mathrm{NH}_{2}$ and Ac-HNP2-NH $\mathrm{NH}_{2}$. We examined their bactericidal activity against E. coli and S. aureus and their ability to induce leakage from large unilamellar vesicles. Loss of the $\mathrm{N}$-terminal positive charge was functionally deleterious, whereas removal of the C-terminal negative charge enhanced microbial killing and membrane permeabilization. Our findings validate the importance of electrostatic forces in defensin-microbe interactions and point to the bacterial cytoplasmic membrane as a target of HNP2 activity.

Keywords: Defensin; HNP

Second, amidation of the C-terminus of HNP2 enhanced bactericidal activity. Alos enhanced ability to interact with memebranes 
There are several characteristics common to these peptides. First, they are all cationic, possessing at least two basic residues occurring at positions 7 and 8 and a free amine at the $\mathrm{N}$-terminal end. Citropin 1.1 is a typical example, with sequence GLFDVIKKVASVIGGL-NH ${ }_{2}$. With the exception of uperin 3.6 (which has an Arg at position 7) all the other peptides have the pattern of Lys7 Lys8. When one of these basic residues is replaced with Ala, the activity of the peptide is reduced remarkably (see citropin synthetic modification 2) but replacement of Asp4 with Ala (citropin synthetic modification 1) does not have any major influence on the activity. Replacement of both basic residues with Ala at positions 7 and 8 results in a lack of observable activity [31]. All the peptides are post-translationally modified to the C-terminal amide and this is vital for their observed activity. The size of the peptides also influences their activities. Sixteen or seventeen residues is the optimal length for these linear peptides (cf. aurein 2.1, citropin 1.1 and 1.2, and uperin 3.5 and 3.6). As the length decreases (cf. aurein 1.1, 1.2 and dahlein 1.2) or increases (cf. maculatin 2.1) the activity decreases.

The solution structures of the

\section{Host-defence peptides of Australian anurans: structure, mechanism of action and evolutionary significance}

Margit A. Apponyi ${ }^{a}$, Tara L. Pukala ${ }^{a}$, Craig S. Brinkwortha

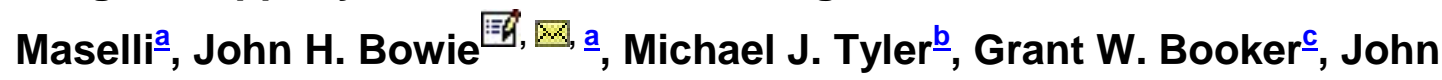
C. Wallace ${ }^{\underline{c}}$, John A. Carver ${ }^{\mathrm{d}}$, Frances Separovic ${ }^{\mathrm{e}}$, Jason Doyle ${ }^{\mathrm{f}}$ and Lyndon E. Llewellyn ${ }^{\mathfrak{f}}$

\section{Peptides}

Volume 25, Issue 6, June 2004, Pages 1035-1054 